\title{
EVALUASI KEBIJAKAN REVITALISASI PASAR TRADISIONAL (Studi Kasus Pasar Sampay Kabupaten Lebak)
}

\author{
Jumanah, Natta Sanjaya, Ipah Mulyani \\ Sekolah Tinggi Ilmu Administrasi Banten
}

*Coressponding Author. Email : Jumanah1011@gmail.com

\begin{abstract}
Local governments hold economic based policies of one another through the revitalization of traditional markets. But the problems found in the field and the basis of important reasons to be researched because there is a problem that is, the first available buildings such as stores and both have not been filled, second lack of customer compliance in complying with regulations, third Market manager has not been adequate in terms of quantity, parking in the market is not well managed, parking is premanism and not managed by the market, obscurity in the market retribution, the five rental costs are given variatively but There are some traders who don't last long. This research aims to determine and assess the trade market revitalization policy as well as its impact on the market Sampay district of Lebak, this researcher uses evaluation indicators namely: effectiveness, adequacy, equalization, responsiveness, accuracy and impact of the policy. The method of research is to use qualitative descriptive. The results of this study showed that the evaluation policy of revitalization of traditional markets (case studies in the market Sampay District Lebak has been successful and has a social impact it can be seen from aspects of (1) responsiveness, society responds well The existence of this market, (2) social impact, that is, change the shopping behavior of shopping habits in the modern market into shopping in the traditional market.
\end{abstract}

Keywords : Impact evaluation, market revitalization policy

\begin{abstract}
Abstrak
Pemerintah daerah menyelenggarakan kebijakan berbasis ekonomi kerakyatan salah satunya melalui revitalisasi pasar tradisional. Namun permasalahan yang ditemukan di lapangan dan menjadi dasar alasan penting untuk diteliti karena ada masalah yaitu, pertama bangunan yang tersedia seperti toko dan los belum diisi, kedua kurangnya kepatuhan pelanggan dalam menaati peraturan, ketiga pengelola pasar belum memadai dalam hal kuantitas, kempat parkir pada pasar tidak terkelola dengan baik, parkir yang ada bersifat premanisme dan tidak dikelola oleh pasar, ketidakjelasan dalam retribusi pasar, kelima biaya sewa yang diberikan bervariatif namun ada beberapa pedagang yang tidak bertahan lama. Penelitian ini bertujuan mengetahui dan menilai Kebijakan revitalisasi pasar tradsional berserta dampaknya di Pasar Sampay Kabupaten Lebak, peneliti ini menggunakan indikator evaluasi yaitu: efektivitas, kecukupan, pemerataan, responsivitas, ketepatan dan dampak Kebijakan. Adapun metode penelitian ini menggunakan deskriptif kualitatif. Hasil penelitian ini menunjukan bahwa evaluasi kebijakan revitalisasi pasar tradisional (studi kasus di pasar Sampay Kabupaten Lebak sudah berhasil dan memiliki dampak sosial hal ini dapat dilihat dari aspek (1) responsivitas, masyarakat merespon dengan baik keberadaan pasar ini, (2) dampak sosial, yaitu mengubah perilaku berbelanja dari kebiasaan berbelanja di pasar modern menjadi belanja di pasar tradisional.
\end{abstract}

Kata Kunci : Evaluasi Dampak, Kebijakan Revitalisasi Pasar 


\section{PENDAHULUAN}

Pasar tradisional merupakan salah satu kekuatan ekonomi rakyat. Peran pasar tradisional penting dalam menghadapi persaingan global karena pelaku pasar tradisonal adalah rakyat kecil yang memiliki modal sedikit, masyarakat petani. Selain itu pasar tradisional menjadi salah satu jantung perekonomian masyarakat. Kedudukan pasar tradisional masih tetap penting dan menyatu dalam kehidupan masyarakat. Banyak masyarakat yang masih membutuhkan pasar tradisional dalam mencari pendapatan dan juga kebutuhan dalam transaksi jual beli.

Beberapa pasar yang sudah masuk Kebijakan revitalisasi pasar, peneliti membatasi pada pasar Sampay, hal ini berdasarkan pengamatan dilapangan bahwa terdapat banyak masalah diantaranya meliputi : pertama, bangunan yang tersedia seperti toko dan los belum diisi. Menurut keterangan informan yang dipaparkan oleh pihak pengelola pasar, hal ini disebabkan toko yang sudah disewa tidak diisi. Hal ini dapat dilihat pada tabel 1

Tabel 1

Jenis Tempat Usaha

\begin{tabular}{cccc}
\hline $\begin{array}{c}\text { Tempat usaha dan } \\
\text { pedagang }\end{array}$ & $\begin{array}{c}\text { Toko } \\
\mathbf{( 3 x 4 )}\end{array}$ & $\begin{array}{c}\text { Kios } \\
\mathbf{( 3 x 3 )}\end{array}$ & $\begin{array}{c}\text { Los } \\
(\mathbf{1 , 2} \mathbf{2} \mathbf{1}) \mathbf{2})\end{array}$ \\
\hline $\begin{array}{c}\text { Jumlah tempat usaha } \\
\begin{array}{c}\text { Jumlah pedagang } \\
\text { yang aktif }\end{array}\end{array}$ & 18 & 83 & 54 \\
\hline $\begin{array}{c}\text { Jumlah sewa } \\
\text { pertahun }\end{array}$ & Rp. 6.000.000 & Rp. 4000.000 & Rp. 1.500 .000 \\
\hline
\end{tabular}

Sumber: Data diolah, 2018

Kedua, kurangnya kepatuhan pelanggan dalam menaati peraturan seperti kepatuhan dalam membayar retribusi, masih terdapat beberapa pedagang yang enggan membayar retribusi, selain itu ketidapatuhan dalam hal menaati batas tempat berjualan hanya diperolehkan satu meter, namun yang terjadi adalah penggunaan lahan pada tempat berdagang melebihi peraturan sehingga tampak semrawut.

Ketiga, pengelola pasar belum memadai dalam hal kuantitas yaitu kurangnya staf seperti bagian kebersihan hanya terdapat satu orang, padahal pasar Sampay memiliki wilayah yang sangat luas selain itu mengenai kualitas tidak diberikan pelatihan manajemen pengelolaan pasar, dan administrasi pasar. Keempat, parkir pada pasar tidak terkelola dengan baik, parker yang ada bersifat premanisme dan tidak dikelola oleh pasar, ketidakjelasan dalam retribusi pasar. Kelima, biaya sewa yang diberikan bervariatif namun ada beberapa pedagang yang tidak bertahan lama akibat masalah financial hal ini ada anggapan bahwa biaya sewa cukup memberatkan terlebih para pedagang harus siap sedia dalam halmodal. Kurangnya transparansi terutama dalam hal sistem sewa yang diberikan kepada pedagang. Minimnya sosialisasi mengenai keberadaan pasar tersebut, mengenai mekanisme tentang sistem sewa tempat berjualan.

Berdasarkan permasalahan tersebut 
di atas, dapat diketahui bahwa Pasar Sampay merupakan pasar perbatasan dengan wilayah Kabupaten Pandeglang, dan merupakan tempat persinggahan transportasi dari Lebak Selatan. Pasar Sampay berdiri pada tahun 2006 dan direvitalisasi melalui Kebijakan pemerintah pada tahun 2012 sudah berjalan lebih dari 4 tahun namun masih banyak permasalahan yang peneliti temukan dilapangan maka peneliti tertarik untuk meneliti "Evaluasi Dampak Kebijakan Revitalisasi Pasar Tradisional diKabupaten Lebak (Studi Kasus pada Pasar Sampay)".

Penelitian mengenai revitalisasi pasar tradisional sebelumnya telah ada yang meneliti, diantaranya yaitu Alfianita dkk, yang berjudul "Revitalisasi Pasar Tradisional dalam Prepektif Good Governance (Studi di Pasar Tumpang Kabupaten Malang)", penelitiannya bertujuan untuk mengetahui, menganalisis, menggambarkan pola kerjasama antar aktor dalam revitalisasi pasar tardisional dalam prespektif good governance, penelitian ini menggunakan metode deskriptif kualitatif dengan hasil penelitian bahwa kerjasama yang telah dilakukan berjalanan dengan baik. Perbedaan penelitian yang telah disusun oleh Alfianita adalah pada konsep dan fenomena yang diamati, jika Alfianita meneliti mengenai kerjasama dan implementasi, penelitiannya menyoroti mengenai evaluasi yaitu untuk menilai dampak dan keberhasilan Kebijakan revitalisasi pasar tradisional.

Penelitian yang telah dilakukan oleh Paskarina dkk dengan judul "Evaluasi Kebijakan Pengelolaan Pasar di Kota Bandung" metode yang digunakan adalah metode ananlisisi kebijakan mengarahkan pada hasil studi komprehensip, dengan hasil penelitian bahwa perlu dilakukan pengelolaan pasar, dimana pasar tradisional ditempatkan sebagai investasi jangka panjang dalam kerangka pengembangan properti kota yang bertujuan untuk meningkatkan dan meredistribusikan capital bagi kesejahteraan masyarakat. Perbedaan penelitian Paskarian dkk dengan penelitian yang peneliti susun adalah pada metode yaitu peneliti menggunakan metode deskriptif kualitatif, selain itu focus penelitiannya juga berbeda jika peneliti sebelumny ahanya melibatkan pada pengelolaan sedangkan penelitian ini melihat pada kebijakan revitalisasi pasar yaitu dilihat dari bangunan, renovasi fisi dan non fisik.

Rumusan dalam Penelitian ini adalah "bagaimana evaluasi dampak social dan ekonomi Kebijakan Revitalisasi Pasar Tradisional di Kabupaten Lebak (Studi Kasus di Pasar Sampay)?"

Penelitian ini bertujuan untuk mengetahui dan menilai Kebijakan revitalisasi pasar tradsional berserta dampaknya di Pasar Sampay Kabupaten Lebak.

\section{METODE PENELITIAN}

Metode yang digunakan dalam penelitian ini adalah metode penelitian explorative dengan pendekatan kualitatif. Metode penelitian explorative adalah metode penelitian yang digunakan untuk meneliti sesuatu (yang menarik perhatian) yang belum diketahui, belum dipahami, belum dikenali dengan baik. Pendekatan ini berupaya menemukan informasi umum mengenai sesuatu masalah yang belum dipahami sepenuhnya oleh seseorang peneliti. 
Penelitian ini menggunakan data primer, yaitu data yang langsung diambil pada lokasi atau lapangan (dari sumbernya), atau data yang masih asli dan masih memerlukan analisis lebih lanjut. Dalam hal ini adalah observasi lapangan dan wawancara. Selain itu dalam penelitian ini juga menggunakan data sekunder, yaitu data yang diperoleh dari atau berasal dari bahan perpustakaan dan peneliti secara tidak langsung melalui media perantara. Dalam penelitian ini adalah study literature dan dokumen kebijakan

Adapun informan dalam penelitian ini yaitu: Dinas Perindustrian dan Perdagangan Kabupaten Lebak, Masyarakat terdiri dari pedagang dan konsumen.

Teknik pengumpulan data yang digunakan dalam penelitian ini adalah dengan mengumpulkan data yang diperlukan sebanyak-banyaknya baik dari data primer dan data sekunder dengan metode wawancara, observasi, dan tenik dokumentasi.

Analisis data menggunakan interactive model of analysis yang dikembangkan oleh Miles dan Hubberman (2013) melalui tiga tahap yaitu reduksi data (data reduction), penyajian data (data display), verifikasi/penarikan kesimpulan (verification).

\section{HASIL DAN PEMBAHASAN Evaluasi Kebijakan Efektivitas}

Berdasarkan wawancara dengan beberapa informan dengan pihak dinas, pedagang maupun konsumen dilihat dari dimensi efektivitas dapat diketahui bahwa ; (1) harapan mereka terhadap keberadaan pasar sampay adalah meningkatkan taraf perekonomian masyarakat, pasar menjadi besar, banyak pengunjungnya dan semua produk yang dibuthkan oleh konsumen lebih bervariatif. (2) kelengkapan sarana dan prasaranapun lengkap seperti ketersedian lahan parkir yang luas, musholla, MCK, tempat sampah. (3) retribusipun berjalan dengan baik, artinya pedagang yang diminta membayarpun dirasakan lancer dan juga tidak memberatkan bagi pedagang, retribusi terdiri dari retribusi jebersihana sebesar Rp. 2000., dan retribusi keamanan sebesar Rp 2.000., namun permasalahnnya retribusi tersebut tidak memiliki dasar hokum atau dalam artian tidak memiliki karcis sebagai tanda bukti pembayaran. (4) hasil dari pasar ini adalah masyarakat sekitar dapat terlibat dalam aktivitas ekonomi dengan menjadi pedagang dan mereka mendapatkan omset meskipun beberapa hasilnya belum sepenuhnya optimal karena pengujung bersifat fluktuatif dan tentatif artinya pengujung kadang sepi kadang ramai, dan biasanya ramai pada hari libur atau hari raya.

\section{Kecukupan}

Berdasarkan wawancara dengan beberapa informan dapat diketahui bahwa: (1) pemerintah sepenuhnya memberikan dukungan, misalnya penyediaan fasilitas yang dibutuhkan oleh semua pihak yang terlibat dalam aktivitas di pasar, (2) masalah yang dihadapi salah satunya adalah masalah keamanan, rawannya kemalingan dan kurang lengkapnya produk-prdouk yang dijual sehingga kurang bervariatif. (3) pemerintah tidak memberikan ijin terhadap pasar malam, memperkeuat keamanan dengan system 24 jam. 


\section{Pemerataan}

Berdasarkan wawancara dengan beberapa informan meliputi pihak dinas dan pihak pedagang dimensi pemerataan terkait syarat-syarat untuk mendapatkan sewa toko dan manfaat keberadaan pasar yang bisa dirasakan oleh semua orang yaitu; (1) syaratsyaratnya dalah pribumi harus memiliki KTP yang foto copy diserahkan kepada pihak pasar, dan mampu membayar biaya tahunan. (2) keberadaan pasar ini mampu memberikan manfaat untuk masyarakat menjadi memiliki pekerjaan atau melakukan aktivitas ekonomi dengan berdagang di pasar.

\section{Responsivitas}

Berdasarkan hasil wawancara perihal respon masyarakat terhadap pembangunan pasar dan kepuasan serta konstribusi masyarakat dengan beberapa pedagang dari fashion, elketronik, sembako, sayuran mereka menyatakan bahwa; (1) masyarakat sekitar merespon, (2) dan mereka puas serta, (3) konstribusi bisa berbelanja dan menjadi pedagang.

\section{Ketepatan}

Berdasarkan wawancara dengan berbagai informan dari pedagang bahwa; (1) yang terpenting memenuhi syarat maka sudah tepat saran tetapi ternyata ada beberapa sebagian yang belum misalnya yang menyewa toko seharusnya 1 toko tapi kemudian memiliki 2 toko, (2) beberapa hal yang tidak sesuai adalah tidak ada karcis pembayaran retribusi, toko-toko sebagian banyak yang kosong terutama bagian belakang. (3) kendatipun pedagan pernah mengusulkan aspirasi meliputi masalah korsesl, masalah keamanan.

\section{Dampak Kebijakan \\ Pertumbuhan Ekonomi}

Berdasarkan hasil wawancara dengan pihak pemerintah, pedagang dan beberapa konsumen dapat diketahui bahwa omset penjualan tidak memiliki progress artinya hari-hari biasa penjualan standar kecuali hari libur atau hari raya, adapun penyerapan lapangan kerja belum sepenuhnya merap lapangan kerja karena beberapa toko dikelola sendiri tidak menggunakan tenaga kerja lain kalaupun menggunakan tenaga kerja lain biasanya hanya satu atau dua orang itupun dari keluarga atau kerabatnya yang bekerja di toko tersebut. Dari segi pendapatan karena beberapa pedagang memiliki penghasilan dari berjualan dan tentunya ini sebagai pendapatan mereka untuk menghidupi perekonomian mereka, adapun daya beli masyarakat tergantung segmen, biasanya daya beli masyarakat lebih condong atau cenderung ke bahan pokok, sedangkan ke toko fashion atau kebutuhan sekunder biasanya ramai pada saat hari raya terutama menjelang lebaran. Produk yang dijual belum lengkap artinya bervariasi seperti tidak ada yang menjual emas, daging dan grosiran, namun pasar ini sebagian menampung produksi hasil pertanian terutama pada sayur mayur. Hal ini menujukan bahwa hasil panen dari petani dapat dijual dipasar dan tentunya memudahkan dan membantu para petani untuk mengkases hasil panennya untuk dijual di pasar.

\section{Dampak Sosial}

Berdasarkan wawancara dengan beberapa informan dapat diketahui bahwa syarat-syarat untuk mendapatkan atau menyewa adalah asli pribumi atau lebih diutamakan pribumi, menyerahkan 
foto copy KTP dan mampu membayar biaya sewa tahunan, setidaknya dengan keberadaan pasar ini dapat mengubah pola prilaku berbelanja terutama masyarakat yang dekat dengan kawasan pasar, beberapa pedagang sebagian sudah bekerja sama dengan pihak lain salah satunya dengan pihak Bank dalam penanaman modal. Pengunjung belum sesuai harapan apa yang dirasakan oleh beberapa pedagang, namun demikan pengunjung lebih banyak ada pada hari libur dan pada hari raya dan tentunya waktu-waktu seperti itu menjadi harapan besar dari para pedagang. Adapun akses menuju pasar mudah, artinya pasar sendiri dekat dengan jalan raya kondisi jalan pun bagus di hotmik serta mudah mendapatkan transportasi umum seperti angkot dan lokasi beada di persimpangan. Dengan keberadaan pasar ini setidaknya mengubah perilaku berbelanja masyarakat disekitar, terjadi interaksi sosial antara pedagang disekitar dengan beberapa konsumen dan tentunya ini akan memperkuat identitas nasional sebagai bangsa dan Negara yang merupakan bagian dari hidup bermasyarakat.

\section{PENUTUP}

Berdasarkan hasil penelitian dilapangan dapat disimpulkan bahwa Evaluasi kebijakan revitalisasi pasar tradisional (studi kasus di pasar Sampay Kabupaten Lebak sudah berhasil dan memiliki dampak sosial hal ini dapat dilihat dari aspek (1) responsivitas, masyarakat merespon dengan baik keberadaan pasar ini, (2) dampak sosial, yaitu mengubah perilaku berbelanja dari kebiasaan berbelanja di pasar modern menjadi belanja di pasar tradisional.

Berdasarkan hasil penelitian, peneliti merekomendasikan saran-saran sebagai berikut :

1. Ketepatan, diperlukan pengawasan dan pengecakan kembali kepada pelaku usaha yang menyewa sehingga benar-benar tepat sasaran, misalnya dengan dibuatkan criteria atau syarat-syarat memperoleh sewa toko.

2. Dampak ekonomi, dilakukan perluasan area bangunan dan mengadakan even-even sehingga menarik pengunjung untuk selalu berbelanja. 


\section{REFERENSI}

Agustino, Leo. 2012. Dasar-Dasar Kebijakan Publik. Bandung : CVAlfabeta

Alfianita, dkk. Revitalisasi Pasar Tradisional dalam Prespektif Good Governance (Studi di Pasar Tumpang Kabupaten Malang. Jurnal Administrasi Publik (JAP),Vol. 3, No. 5, Hal. 758-762 | 760

Biro Pusat Statistik Provinsi Banten Biro Pusat Statistik Kabupaten Lebak DPD.2015. Peran Pasar Tradisional Sebagai Pondasi Dasar Ekonomi Kerakyatan tgl 30 januari 2017 http://www.dpd.go.id/artikel-957peran-pasar-tradisional-sebagaipondasi-dasar-ekonomi-kerakyatan

LAKIP Dinas Perindustrian dan Perdagangan Kabupaten Lebak

Moleong, Lexy. 2011. Metodologi Penelitian Kualitatif. Bandung. Rosda

Paskarina, Caroline, dkk.2007. Evaluasi Kebijakan Pengelolaan Pasar di Kota Bandung. Bandung. Lembaga Penelitian Universitas Padjajaran
Pasolong, Harbani. 2014. Teori Administrasi Publik. Bandung. Alfabeta

Permendagri No 20 Tahun 2012

Rencana Strategis Dinas Perindustrian dan Perdagangan Kabupaten Lebak

Subarsono.2013. Analisis Kebijakan Publik Konsep, Teori dan Aplikasi. Yogyakarta:PustakaPelajar

Sugiyono. 2013. Metode Penelitian Manajemen. Bandung.Alfabeta

Wahab, Solichin Abdul.2012. Analisis Kebijakan dari Formulasi ke Penyusunan Model-Model Implementasi Kebijakan Publik. Jakarta. PT.Bumi Aksara

Wicaksono, dkk. Persepsi Pedagang Pasar terhadap Kebijakan Perlindungan Pasar Tradisional oleh Pemerintah Kota Semarang. Penelitian http://download.portal garuda.org diakses tgl 2 Januari 2017

Widodo, Tri.2013. Studi Tentang Peranan Unit Pasar dalam Pengelolaan Sampah di Pasar Merdeka Kota Samarinda Studi Tentang Peranan Unit Pasar. 